\title{
Using Synchrotron-Based X-Ray Microcomputed Tomography to Characterize Water Distribution in Compacted Soils
}

\author{
Zhong-Sen Li $\mathbb{D}^{1}$ and Lian-Sheng Tang $\mathbb{D}^{2,3}$ \\ ${ }^{1}$ Assistant Researcher and Post-Doctor, School of Earth Sciences and Engineering, Sun Yat-Sen University, No. 135, \\ Xingang Xi Road, 510275 Guangzhou, China \\ ${ }^{2}$ Professor, School of Earth Sciences and Engineering, Sun Yat-Sen University, Guangzhou, China \\ ${ }^{3}$ Guangdong Provincial Key Laboratory of Geological Processes and Mineral Resource Survey, No. 135, Xingang Xi Road, \\ 510275 Guangzhou, China
}

Correspondence should be addressed to Lian-Sheng Tang; eestls@mail.sysu.edu.cn

Received 3 November 2018; Revised 1 March 2019; Accepted 8 April 2019; Published 2 May 2019

Academic Editor: Claudio Pettinari

Copyright ( 2019 Zhong-Sen Li and Lian-Sheng Tang. This is an open access article distributed under the Creative Commons Attribution License, which permits unrestricted use, distribution, and reproduction in any medium, provided the original work is properly cited.

\begin{abstract}
Water plays a vital role on the hydromechanical behavior of unsaturated soils. An important concern in unsaturated soil mechanics is to determine the distribution of water within voids and its interaction with soil grains. This paper presents some results of the spatial distribution of water in different soils using the synchrotron-based X-ray microcomputed tomography $(\mu$-CT). Three materials (glass beads, natural sand, and clay) were first prepared at a water content of about $10 \%$, statically compacted under vertical total stress of $500 \mathrm{kPa}$, and then scanned by synchrotron X-rays at an energy of $18 \mathrm{or} 20 \mathrm{keV}$. The threedimensional (3D) microstructure of the samples including air, liquid, and solid phases was reconstructed, and some new observations were obtained: (i) the iodine-based contrast medium (KI) can increase the peak greyscale value of water from 110 to 122, enhance the air-water contrast, and thus facilitate the segmentation of water phase; (ii) in the compacted glass beads and sand, water distribution is characterized using the $\mu$-CT and image reconstruction technique. The water contents obtained by phase segmentation, i.e., $10.2 \%$ and $9.3 \%$, are comparable with those measured by the oven-drying method, i.e., $9.7 \%$ and $9.4 \%$ for the glass beads and sand, respectively; (iii) water is preferably distributed within aggregates when it is mixed with the oven-dried particles, and an aggregate-dominated 3D structure is observed. However, it is impossible to determine the water phase for the studied material even with the resolution of $0.65 \mu \mathrm{m} /$ pixel.
\end{abstract}

\section{Introduction}

In traditional soil mechanics and engineering practice, research related to the microstructure of soils was mostly limited to two-dimensional (2D) distribution of soil particles and voids generally using scanning electron microscope and mercury intrusion porosimetry [1-3]. With the development of technology, the X-ray $\mu$-CT has recently been proved to be effective in 3D characterization of soils, and it has been used (i) to quantify the porosity or voids [4-14], (ii) to investigate the strain localization (e.g., [15-22]), (iii) to characterize the particle breakage (e.g., [15, 23-27]), (iv) to investigate the particle morphology and orientation [28-31], and (v) to estimate the particle strains and rotations [17, 25, 32-37].
The main parameters of the X-ray $\mu$-CT tests are presented in Table 1, showing very interesting features in terms of resolution, total acquisition time, and sample size for different materials.

As liquid phase is concerned, the application of the $\mu$-CT to characterize the water distribution was more complex and less reported $[14,44]$. When a beam of X-rays penetrates a medium, its intensity will be attenuated. At a given photon energy, the degree of attenuation (e.g., the linear attenuation coefficient) is normally related to the atomic number of the medium; the larger the atomic number is, the larger the linear attenuation coefficient will be. As multiphase unsaturated soil is concerned, Figure 1(a) shows the linear attenuation coefficients of air, water, and solid (e.g., quartz) 
TABLE 1: Main parameters of recent X-ray $\mu$-CT tests on soils in the literature.

\begin{tabular}{|c|c|c|c|c|c|c|c|c|c|}
\hline \multirow{2}{*}{$\begin{array}{l}\text { X-ray } \\
\text { sources }\end{array}$} & \multicolumn{3}{|c|}{ Detector } & \multicolumn{3}{|c|}{ Projection } & \multicolumn{2}{|c|}{ Sample size } & \multirow[b]{2}{*}{ Reference } \\
\hline & $\begin{array}{l}\text { Pixel size } \\
(\mu \mathrm{m})\end{array}$ & No. of pixels & $\begin{array}{c}\text { Field of } \\
\text { view }(\mathrm{mm})\end{array}$ & $\begin{array}{l}\text { Exposure } \\
\text { time }(\mathrm{s})\end{array}$ & $\begin{array}{c}\text { No. of } \\
\text { projections }\end{array}$ & $\begin{array}{l}\text { Total acquisition } \\
\text { time (min) }\end{array}$ & $D(\mathrm{~mm})$ & $H(\mathrm{~mm})$ & \\
\hline \multirow{7}{*}{$\mathrm{X}$-ray tube } & 11.2 & $2316 \times 2316$ & $25.9 \times 25.9$ & 2 & 1000 & 1 & 10 & 23 & {$[8]$} \\
\hline & 75.7 & & $77.5 \times 77.5$ & \multirow{3}{*}{$\begin{array}{l}0.5 \\
2.4\end{array}$} & 1200 & & \multirow{3}{*}{35} & \multirow{3}{*}{70} & \multirow{3}{*}[19]{} \\
\hline & 7.6 & $1024 \times 1024$ & $7.8 \times 7.8$ & & 4800 & 20 & & & \\
\hline & 4.2 & & $4.3 \times 4.3$ & & 4800 & & & & \\
\hline & 9 & $4008 \times 2672$ & $36 \times 24$ & \multirow[t]{2}{*}{0.2} & \multirow{2}{*}{1440} & \multirow[t]{2}{*}{90} & \multirow[t]{2}{*}{50} & \multirow[t]{2}{*}{10} & \multirow{2}{*}[12]{} \\
\hline & 127 & $1920 \times 1526$ & $244 \times 194$ & & & & & & \\
\hline & 3.3 & $2000 \times 2000$ & $6.6 \times 6.6$ & I & I & 90 & 1 & I & {$[27]$} \\
\hline \multirow{8}{*}{$\begin{array}{l}\text { Synchrotron } \\
\text { radiation }\end{array}$} & & $2048 \times 2048$ & $28.7 \times 28.7$ & 0.08 & \multirow{2}{*}{1200} & 5 & 10 & 20 & \multirow{2}{*}[38]{} \\
\hline & 14 & $1024 \times 1024$ & $14.3 \times 14.3$ & 0.04 & & 2.5 & 20 & 40 & \\
\hline & 14 & 1 & I & I & I & 12 & 11 & 22 & [17] \\
\hline & 2.2 & $4008 \times 2672$ & $8.8 \times 5.9$ & 2 & 3600 & 120 & l & I & [39] \\
\hline & 7.5 & $2680 \times 1300$ & $20.1 \times 9.75$ & $1.8-2.2$ & l & $180-240$ & 8 & 4 & {$[40]$} \\
\hline & 4.4 & 1 & 1 & 1 & 1440 & $60-90$ & \multicolumn{2}{|c|}{$3 \times 4 \times 5$} & [41] \\
\hline & 0.33 & I & $0.8 \times 0.6$ & 0.09 & 1501 & I & 0.5 & I & {$[42]$} \\
\hline & 0.5 & 1 & 1 & 0.3 & 1500 & I & $<1$ & $<1$ & [43] \\
\hline
\end{tabular}

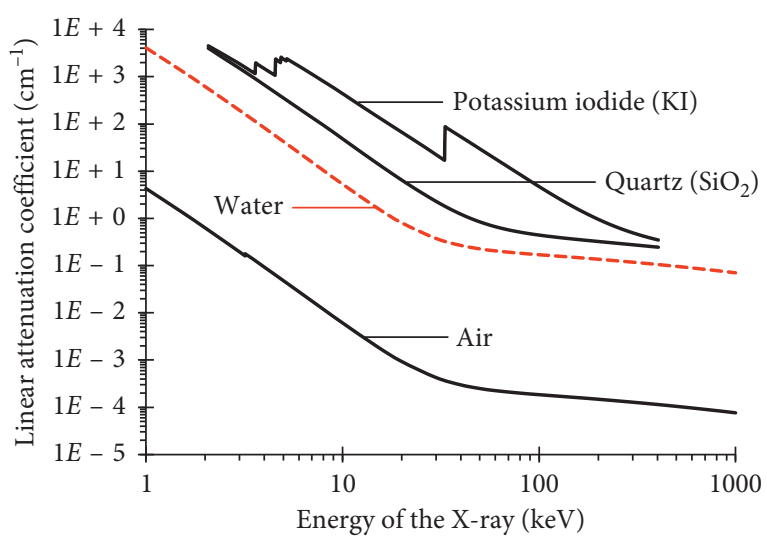

(a)

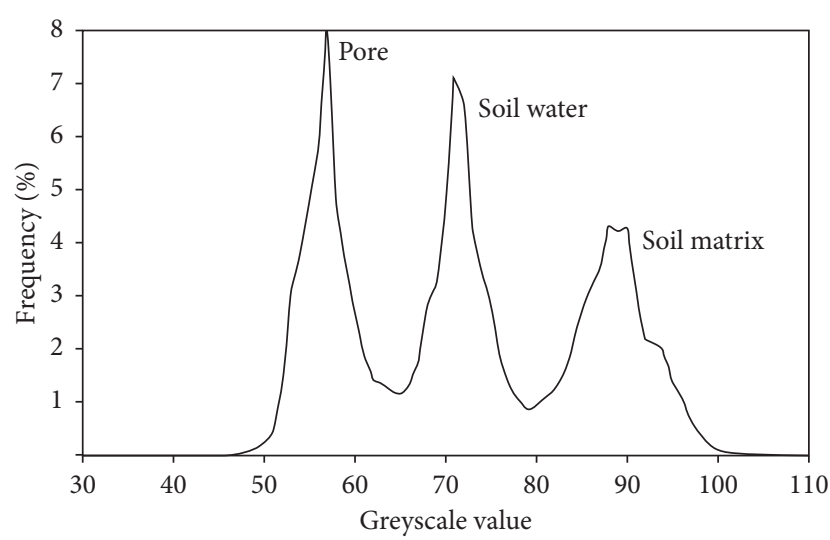

(b)

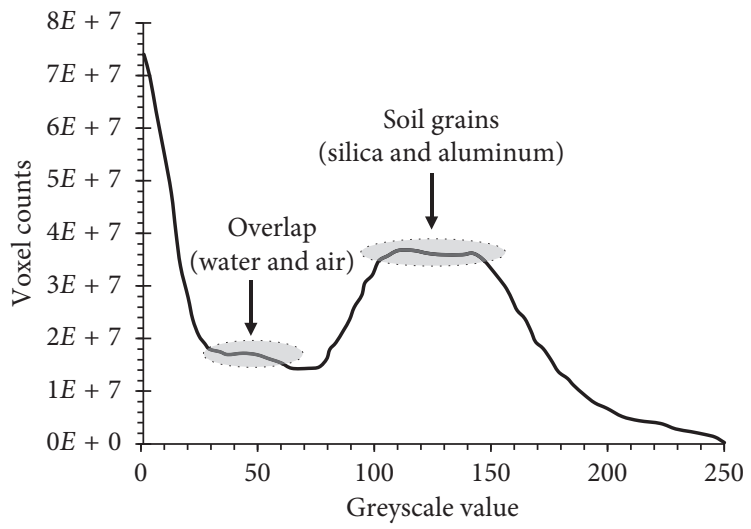

(c)

FiguRE 1: Linear attenuation coefficient of different phases in soil and the corresponding greyscale histogram. (a) Linear attenuation coefficients of air, water, quartz, and potassium iodide at X-ray energies from 1 to $1000 \mathrm{keV}$ (data from [45] and the online FFAST database of the National Institute of Standards and Technology, USA). (b) Greyscale histogram of an undisturbed loess (from [46]). (c) Greyscale histogram of a compacted sand (from [9]).

versus the increasing X-ray energy. Due to the difference in linear attenuation coefficient of different phases, the soil grains usually seem "darker" than air in the CT projections, whereas they feature a "lighter" color in the reconstructed CT slices. The degree of such brightness can be quantitatively reflected by the histogram of the greyscale value of the slice, 
as presented in Figure 1(b) (from [46]). Based on the greyscale histogram, water is detectable and can be directly segmented using its distinctive peak greyscale value. In some cases, however, the situation may be different and complex; for example, the overlap in greyscale value between air and water phases was reported in [9], where the peaks of air and water in the greyscale histogram are completely merged, and it is impossible to simply separate the two phases (Figure 1(c)). To solve this problem, effort has been made either to enhance the air-water contrast by adding iodinebased or chlorine-based contrast medium in water (e.g., $[14,47,48]$ or to directly capture water phase using neutron radiography $[8,9,49,50])$.

In this paper, synchrotron-based X-ray $\mu$-CT tests were performed on three statically compacted soils, e.g., glass beads, natural sand, and clay, from engineering site. Water distribution and morphology within typical compacted soils were determined and compared. The main contributions consist of the following:

(i) Quantitatively demonstrating the effect of the contrast medium (i.e., $\mathrm{KI}$ in this study) on the greyscale value of the liquid phase

(ii) Extending the idealized material (e.g., glass beads or sand in the literature) to the "real" soil (e.g., clay from the engineering site) and highlighting some difficulties in characterizing water distribution within clayey soil.

\section{Materials and Methods}

Three materials, namely, BioSpec glass bead, Zhuhai sand, and Guangzhou clay, were selected. BioSpec glass bead is a commercially available product from BioSpec Products Inc. (USA), with a diameter of about $0.2 \mathrm{~mm}$. Zhuhai sand is a local material of Zhuhai, located alongside the South China Sea. Guangzhou clay was extracted from a slope of the Guangzhou metro line No. 21. It is a typical tropical laterite that is widely distributed in the south of China. The grain size distributions of the materials are presented in Figure 2.

The materials were first put into an oven at a temperature of $105^{\circ} \mathrm{C}$ for two days. Then, $500 \mathrm{~g}$ of the dried soil grains was carefully mixed with (i) $50 \mathrm{~g}$ deionized water or (ii) $60 \mathrm{~g} \mathrm{20 \%}$ (weight) KI solution, aiming to reach a target water content of $10 \%$. Due to the high solubility in water and large relative contrast value [51], KI was used in this study to enhance the phase contrast. The $10 \%$ moist soils were sealed in an aluminum box for about two days to arrive at equilibrium, then taken out, and statically compacted in a $5 \mathrm{~mm}$ diameter stainless steel tube by applying a vertical stress of $500 \mathrm{kPa}$. After compaction, the tube was sealed with silica gel at each end and fixed on the magnetic base that can be firmly attached to the stainless-steel rotation stage (Figure 3).

$\mathrm{X}$-rays were generated in the beam-line BL13W1 of Shanghai Synchrotron Radiation Facility (SSRF). Compared with the X-rays produced in X-ray tubes (e.g., for industrial and medical applications), the synchrotron-based $\mathrm{X}$-rays are monochromatic (identical photon energy) and have a much higher brilliance. This can avoid beam hardening effect,

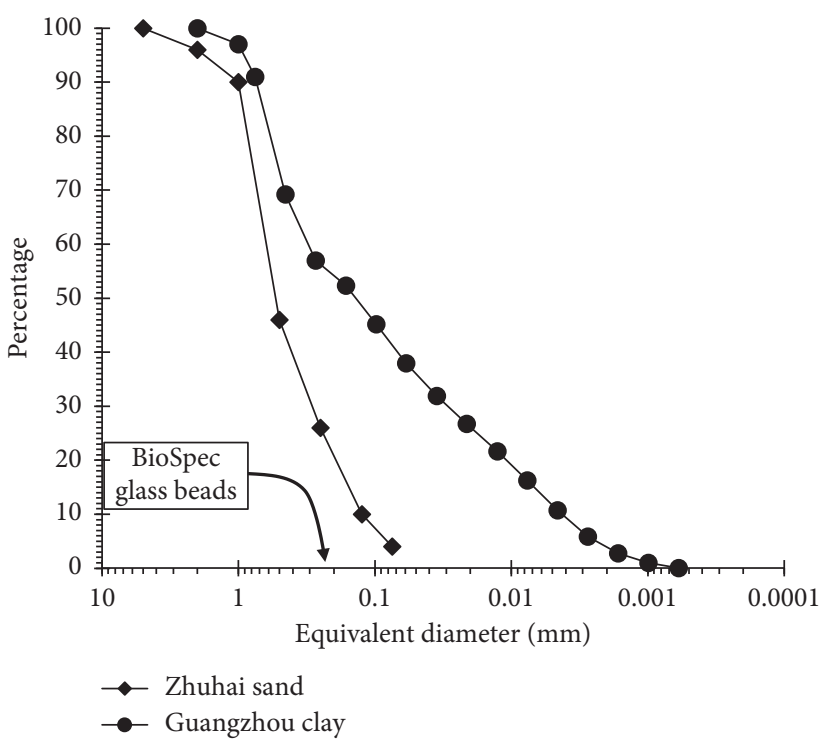

FIGURE 2: Grain size distribution of the studied materials.

reduce artefacts, and thus significantly improve the quality of the reconstructed images. The optical transform system (Optique Peter PCO2000) provides multiobjectives, with magnification ranging from 1.25 to 20 times the original size. The charge coupled device (CCD) detector (Hamamatsu ORCA-Flash4.0) has a field of view of $13.0 \times 13.0 \mathrm{~mm}$ with $2048 \times 2048$ pixels, corresponding to the pixel size of $6.5 \mu \mathrm{m}$ in each direction. In the study, samples of BioSpec glass beads and Zhuhai sand were scanned using the $2 \mathrm{X}$ objective lens, whereas in the case of Guangzhou clay, samples were firstly scanned with the $2 \mathrm{X}$ objective lens and then with the 10X objective. The applied photon energy is $18 \mathrm{keV}$ for the BioSpec glass beads and $20 \mathrm{keV}$ for the rest. 1200 projections were recorded while the sample was rotated $180^{\circ}$. The whole scanning process took about 30 and 150 minutes for the $2 \mathrm{X}$ and 10X objectives, respectively (Table 2 ).

After CT scan, the 1200 projections (about $5 \mathrm{~Gb}$ ) were imported into the open-source phase retrieval software PITRE [52]. PITRE provides algorithms to reconstruct the soil structures and outputs 1200 or 2000 slices (greyscale images) containing the greyscale information of each phase of the soil. 3D structure was reconstructed by stacking the slices in the commercial software Avizo Fire 8. Further analysis such as phase segmentation and volume calculation was realized based on the specific greyscale value of air, water, and soil grains in the reconstructed images (Figure 4).

\section{Results and Discussion}

3.1. Effect of Contrast Media on X-Ray Imaging. Figures 5(a) and 5(b) present the slice (no. 504) and greyscale histogram of the Zhuhai sand prepared with deionized water. In the slice image (enlarged view), air, water, and soil grains are qualitatively distinguishable, whereas in the corresponding histogram, the peaks of air and water phases are completely merged, the same as that reported in [9]. 


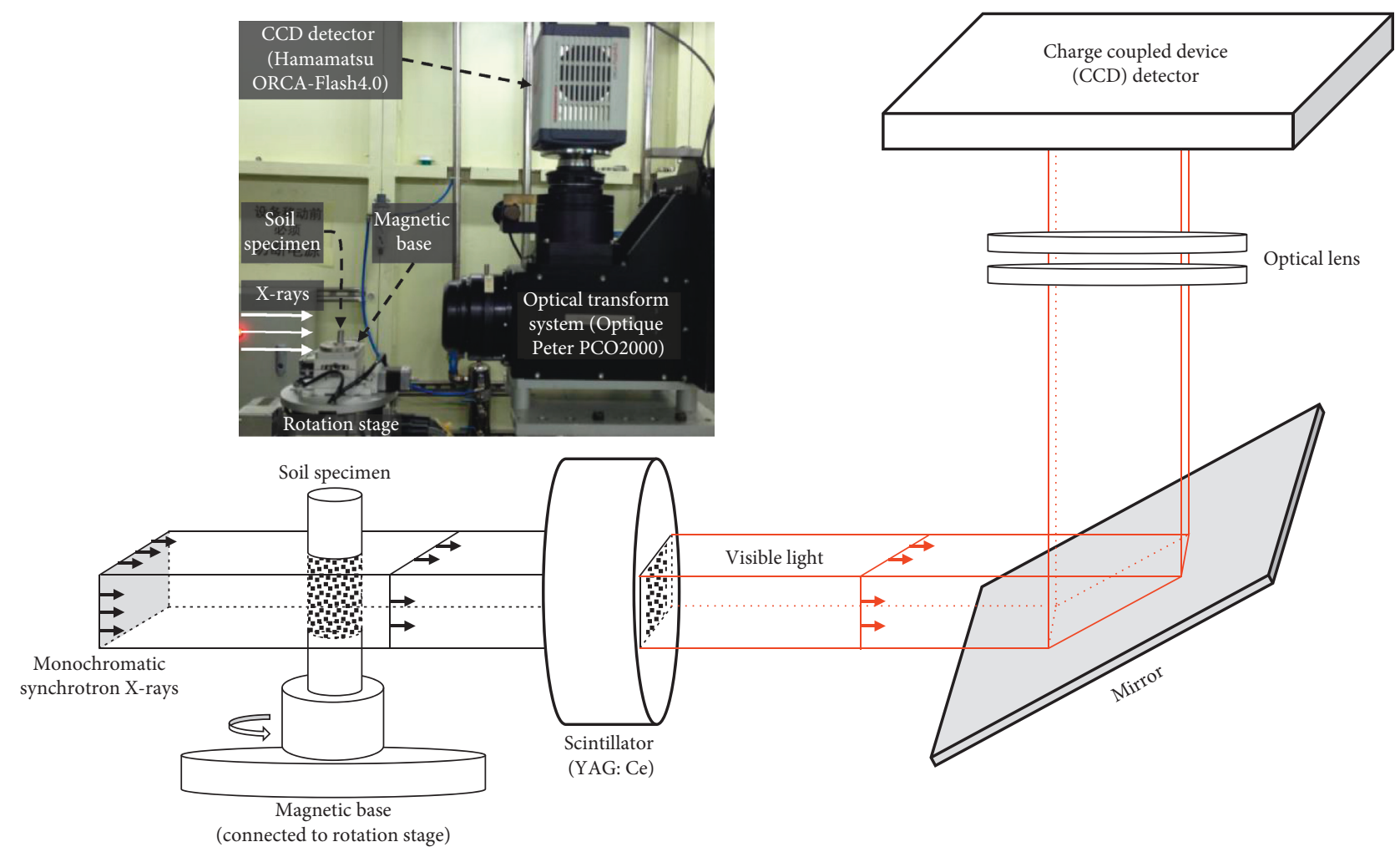

Figure 3: Experimental setup of the $\mu$-CT at the BL13W1 SSRF.

TABLE 2: Tests performed in this study.

\begin{tabular}{|c|c|c|c|c|c|c|c|c|}
\hline \multirow{2}{*}{ Materials } & \multirow{2}{*}{$\begin{array}{c}\text { Sample size } \\
\text { Diameter } \\
(\mathrm{mm})\end{array}$} & \multicolumn{6}{|c|}{ CT test } & \multirow{2}{*}{$\begin{array}{c}\text { Sample } \\
\text { reconstruction } \\
\text { No. of slices }\end{array}$} \\
\hline & & $\begin{array}{c}\text { Photon energy } \\
(\mathrm{keV})\end{array}$ & $\begin{array}{c}\text { Objective } \\
\text { lens }\end{array}$ & $\begin{array}{l}\text { Pixel size } \\
(\mu \mathrm{m})\end{array}$ & $\begin{array}{c}\text { No. of } \\
\text { pixels }\end{array}$ & $\begin{array}{l}\text { Field of view } \\
(\mathrm{mm})\end{array}$ & $\begin{array}{l}\text { Acquisition time } \\
(\mathrm{min})\end{array}$ & \\
\hline $\begin{array}{l}\text { BioSpec glass } \\
\text { beads }\end{array}$ & 5 & 18 & $2 \mathrm{X}$ & 3.25 & $2048 \times 2048$ & $6.7 \times 6.7$ & 30 & 1200 \\
\hline Zhuhai sand & 5 & 20 & $2 \mathrm{X}$ & 3.25 & $2048 \times 2048$ & $6.7 \times 6.7$ & 30 & 1200 \\
\hline Guangzhou & 5 & 20 & $2 \mathrm{X}$ & 3.25 & $2048 \times 2048$ & $6.7 \times 6.7$ & 30 & 1200 \\
\hline clay & 1 & 20 & $10 \mathrm{X}$ & 0.65 & $2048 \times 2048$ & $1.3 \times 1.3$ & 150 & 2000 \\
\hline
\end{tabular}

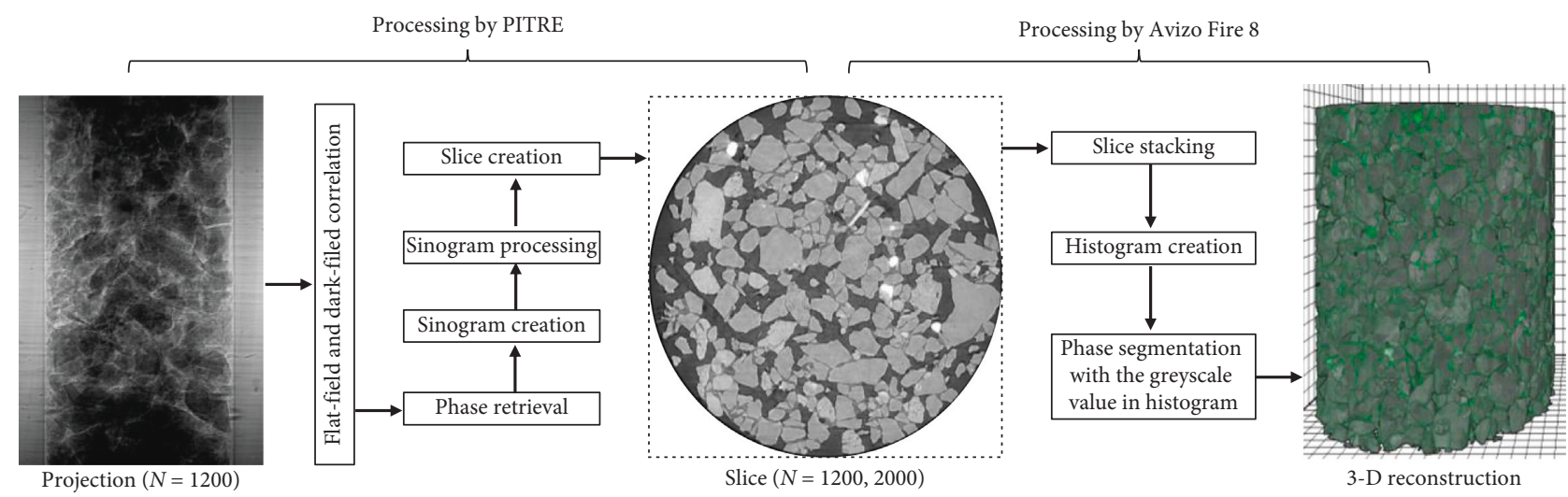

Figure 4: Phase retrieval, slice creation, and 3D reconstruction of a soil sample.

When contrast medium (KI) is added, no significant improvement of the air-water contrast is observed from the slice (no. 360) in Figure 5(c). However, in the greyscale histogram, the greyscale value of the water phase slightly increases from 110 to 122 , and as a result, the peaks of air and water phases become clearer and separated (Figure 5(d)). 


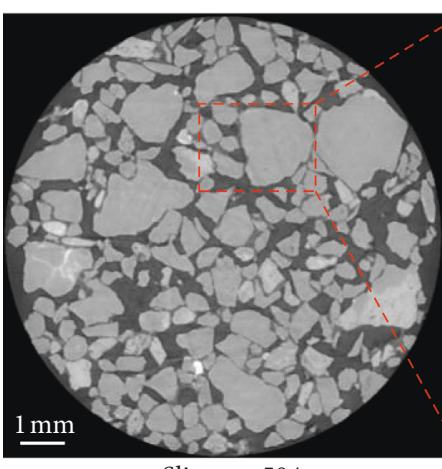

Slice no. 504

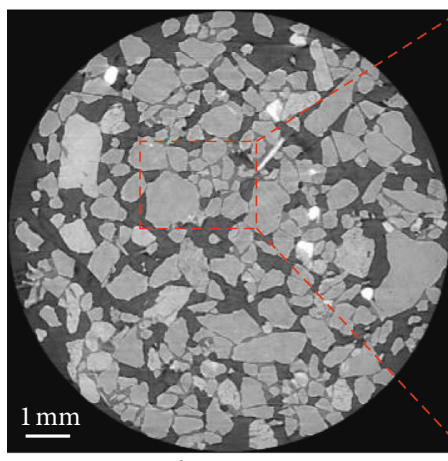

Slice no. 360

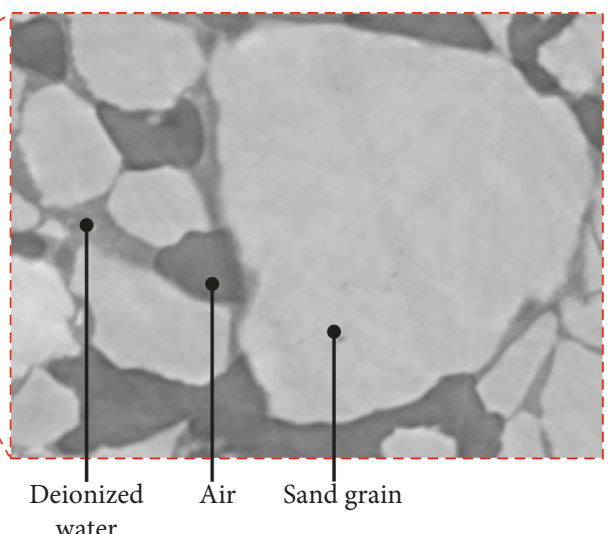

(a)

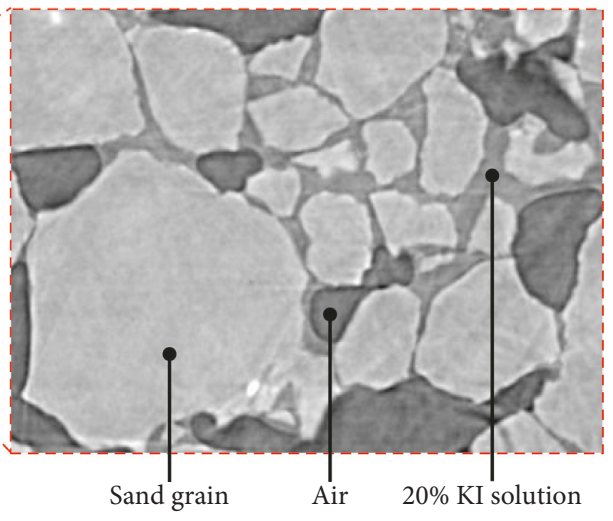

(c)

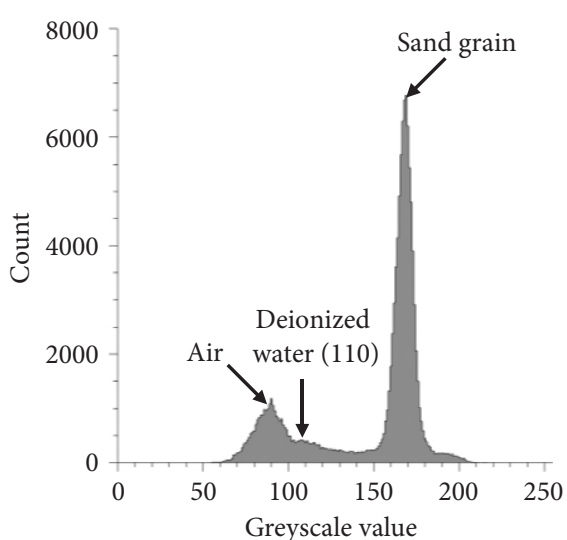

(b)

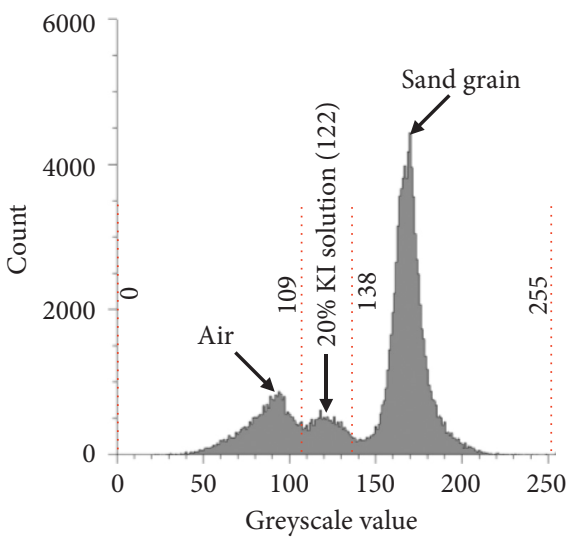

(d)

FIGURE 5: Slice image and greyscale histogram of the compacted Zhuhai sand. (a) Slice image and (b) histogram of the sand mixed with deionized water. (c) Slice image and (d) histogram of the sand mixed with $20 \%$ KI solution.

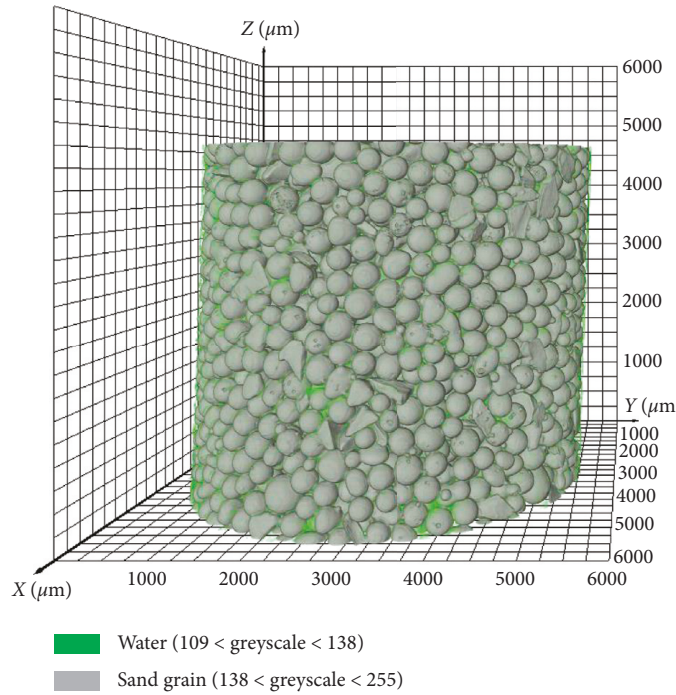

(a)

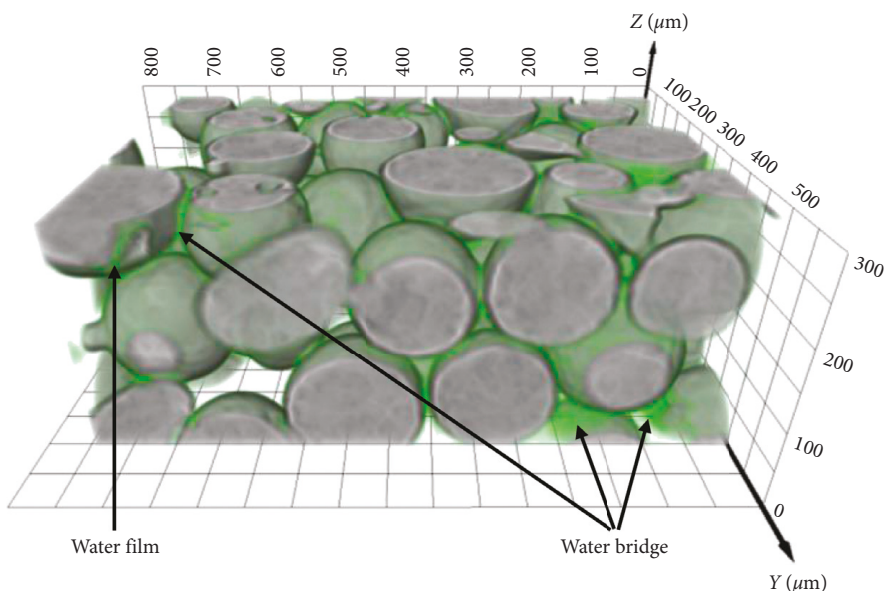

(b)

FIgURE 6: Continued. 


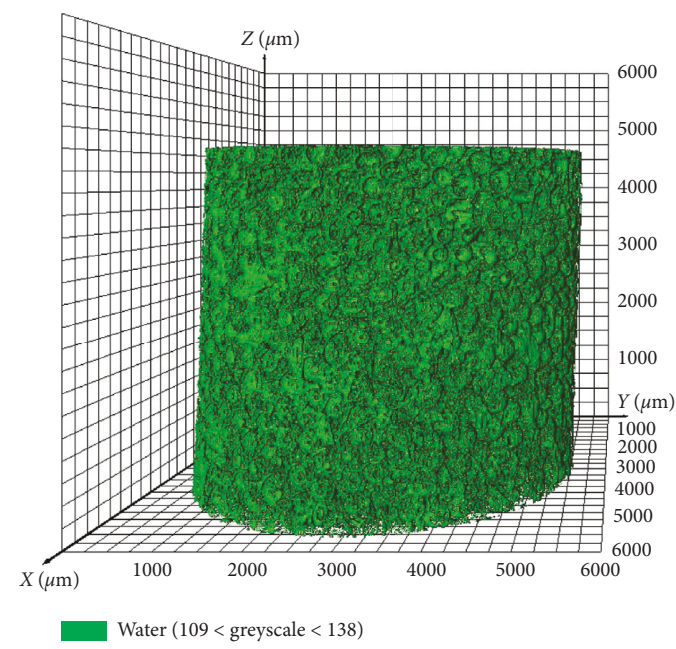

(c)

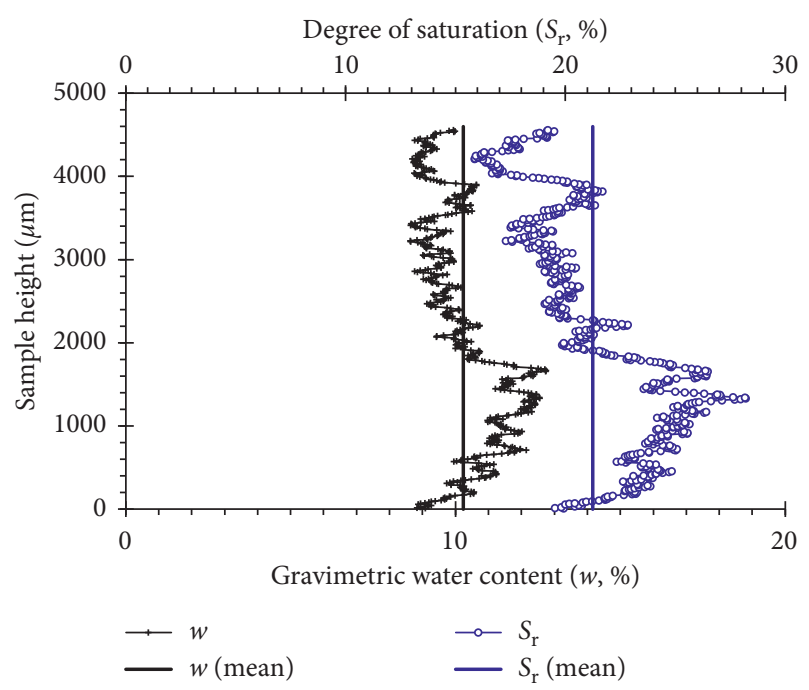

(d)

FIgURE 6: 3D reconstruction and water distribution within the compacted BioSpec glass beads. (a) 3D reconstruction. (b) Enlarged view. (c) Segmented water phase. (d) Profile of water content and degree of saturation.

TABLE 3: Water content determined by different methods.

\begin{tabular}{lccc}
\hline Water content (\%) & Glass beads & Zhuhai sand & Guangzhou clay \\
\hline Target & 10 & 10 & 10 \\
Oven-dried & 9.7 & 9.4 & 9.6 \\
Phase segmented & 10.2 & 9.3 & $/$ \\
\hline
\end{tabular}

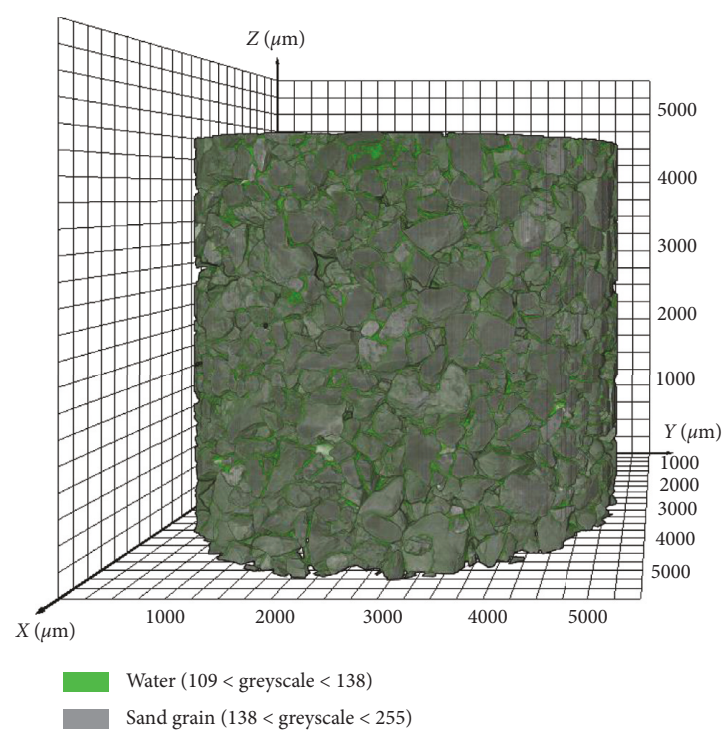

(a)

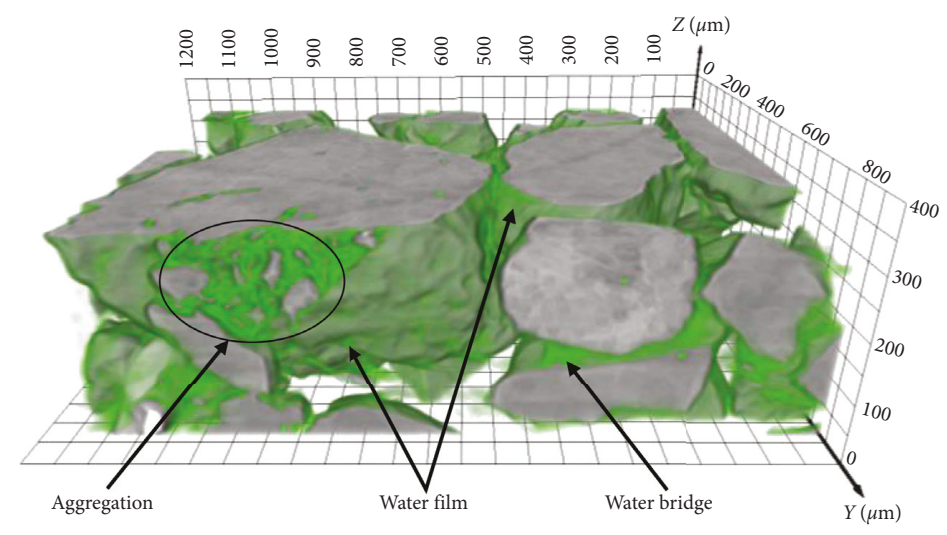

(b)

Figure 7: Continued. 


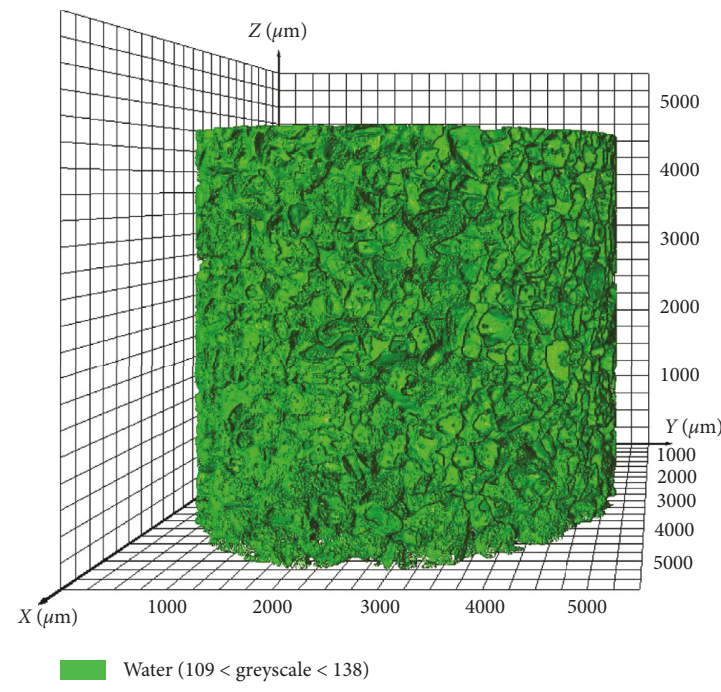

(c)

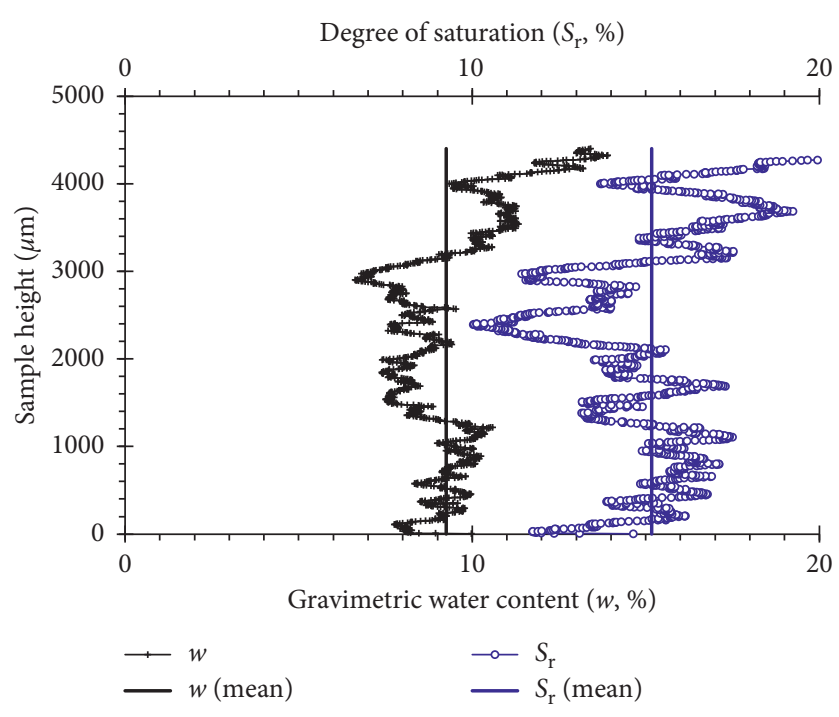

(d)

FiguRE 7: 3D reconstruction and water distribution within the compacted Zhuhai sand. (a) 3D reconstruction. (b) Enlarged view. (c) Segmented water phase. (d) Profile of water content and degree of saturation.

The above results quantitatively show the capability of KI to enhance the air-water contrast, which contributes to (semi) automatic segmentation of water. Qualitative results on other contrast media such as $\mathrm{CsCl}$ were also reported (e.g., $[14,48]$ ). In addition to the above iodine-based or chlorine-based contrast media, Van Loo et al. [51] reported a total of 50 other contrast media and their ability to enhance the X-rays imaging of water. Note that, as the addition of contrast medium changes the contact angle of water, it is necessary to consider such an effect when new contrast medium is considered. In this study, 20\% KI has negligible influence on the contact angle as the capillary rise of KI solution was found to be almost the same as that of deionized water.

\subsection{Water Distribution in Compacted Glass Beads and Sand.} Figure 6 shows the reconstructed 3D structure of the compacted BioSpec glass beads. In Figure 6(a), water phase was segmented and highlighted in green color based on its distinctive greyscale values ranging from 109 to 138 . An enlarged view is presented in Figure 6(b) to show the detailed information in particular the water bridge between grains. The general picture of the water morphology (Figure 6(c)) reflects the complexity and heterogeneity of the structure of water within the sample. Quantitatively, the gravimetric water content (calculated with the number of pixels of air, water, and grains) varies from 8.8 to $12.7 \%$ alongside the sample height direction (Figure 6(d)). The degree of saturation deviates about $\pm 5 \%$ from the mean value, $21.2 \%$. The mean value of the water content is $10.2 \%$, which is a bit larger than the target water content and that measured by oven-drying (Table 3). The main reason for such high water content probably results from the effect of adding KI on the quantification of water. In fact, to prepare the sample with a target gravimetric water content of $10 \%$, $60 \mathrm{~g} \mathrm{20 \%}$ (weight) KI solution was mixed with $500 \mathrm{~g}$ glass

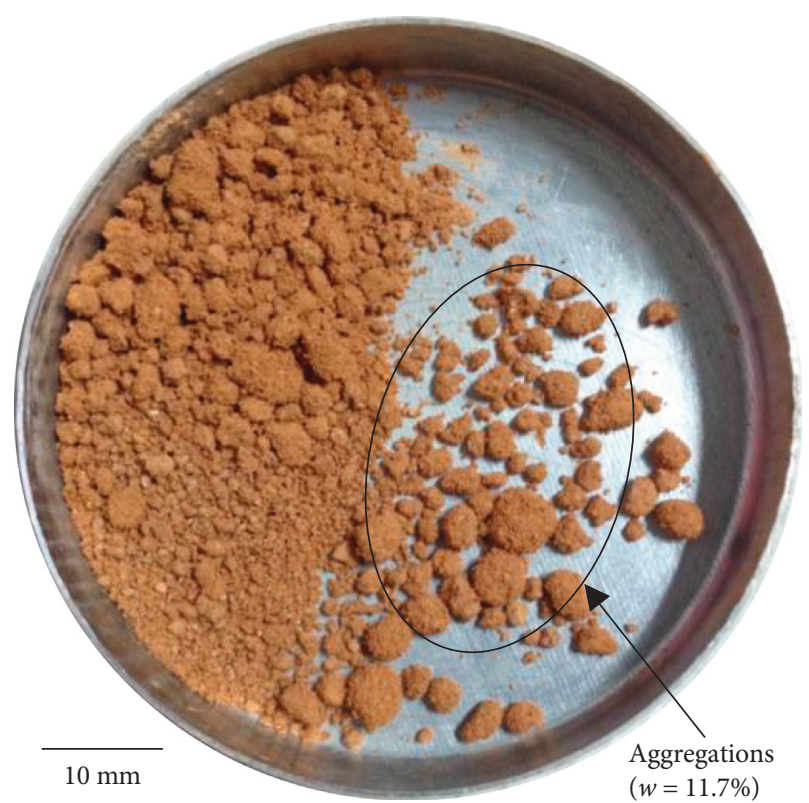

FIGURE 8: Formation of aggregates after mixing water with ovendried clay particles.

beads. The volume of liquid phase (i.e., KI solution) is about $27.65 \%$ of that of the soil grains (glass beads) by considering the densities of $20 \%$ KI solution and glass beads to be 1.15 and $2.65 \mathrm{~g} / \mathrm{cm}^{3}$, respectively. Assuming another sample of gravimetric water content of $10 \%$ by mixing $50 \mathrm{~g}$ deionized water with $500 \mathrm{~g}$ soil grains, the ratio of the water volume to grain volume is $26.5 \%$, showing that adding the contrast medium into soil, as presented in this study, will 1.15\% overestimate the quantity of segmented liquid phase.

Figure 7 presents the 3D structure of the Zhuhai sand. In the compacted sample (Figure 7(b)), water is preferably distributed within aggregates that mainly consist of small 


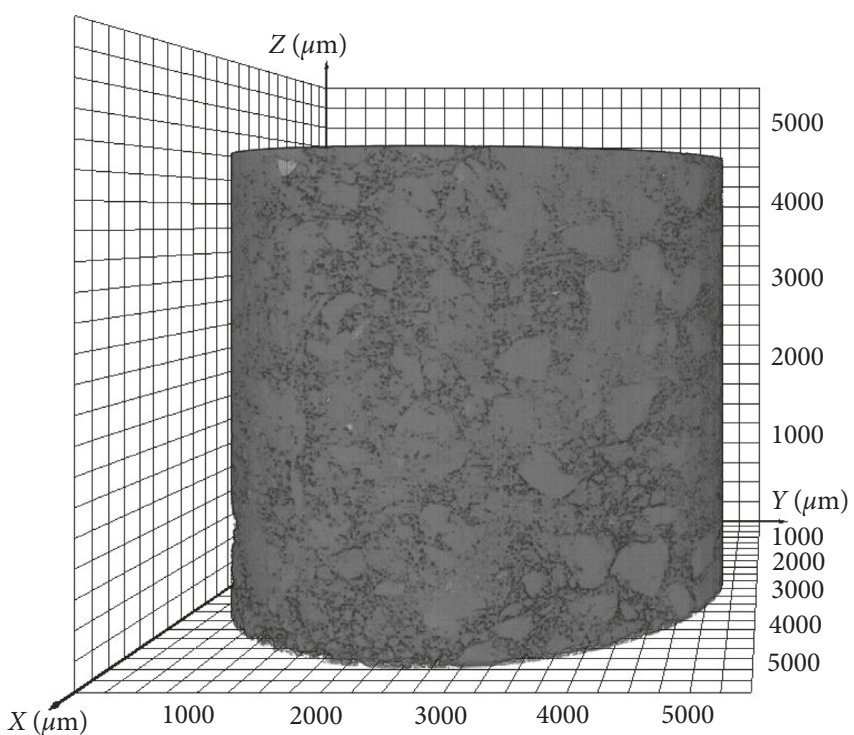

(a)

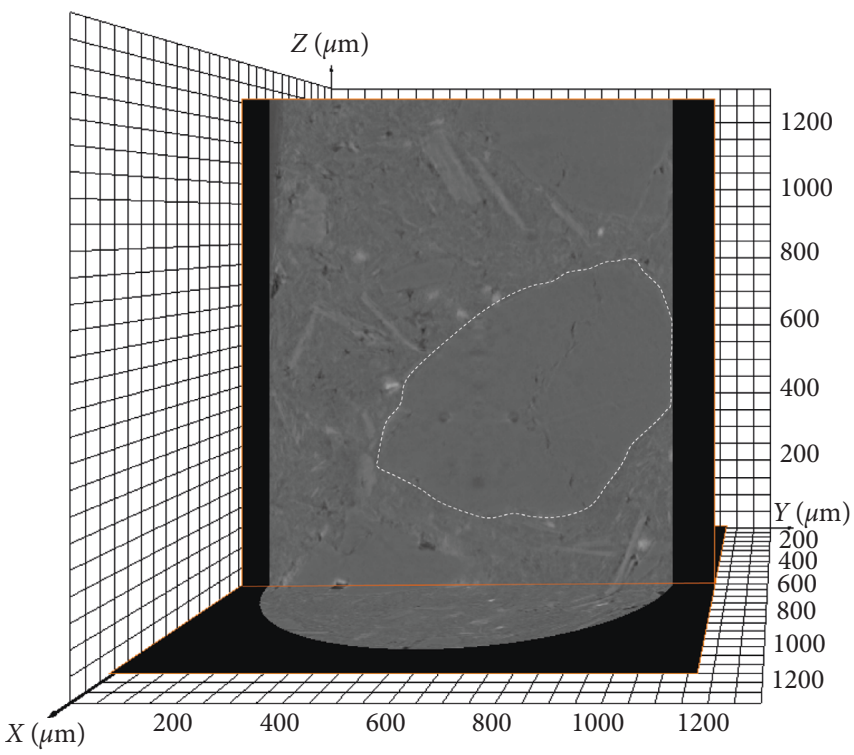

(c)

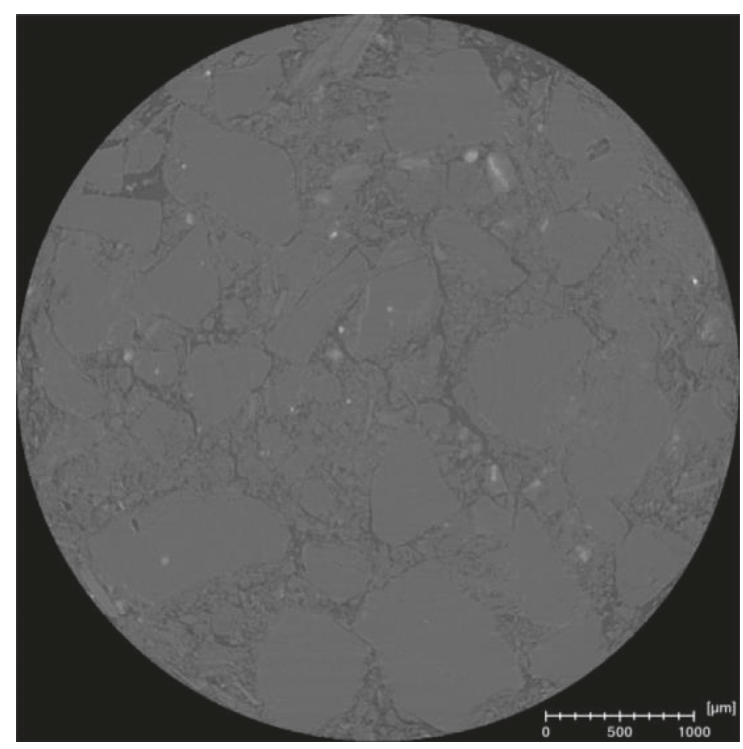

(b)

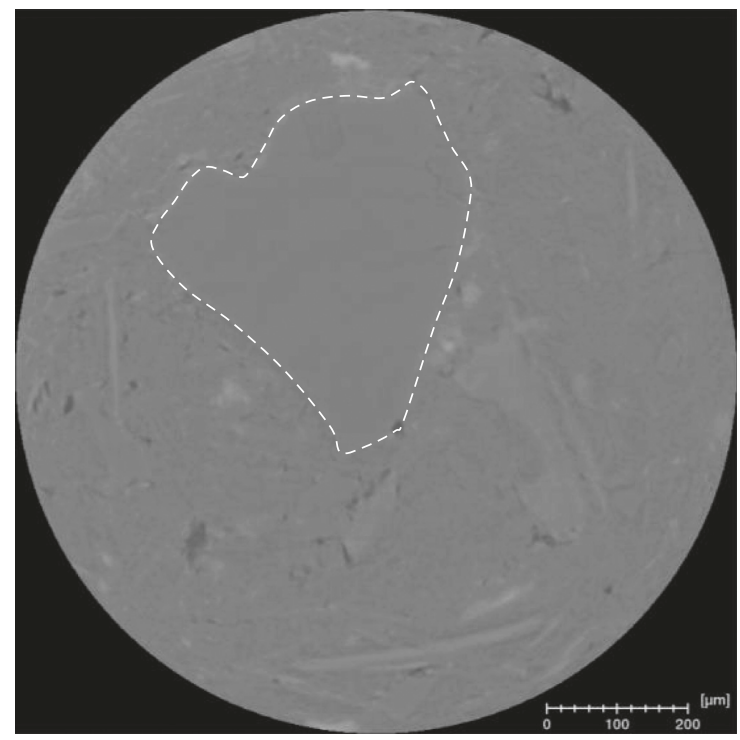

(d)

Figure 9: Aggregates-dominated structure of the compacted Guangzhou clay scanned with two different objective lens. (a) 3D reconstruction with the $2 \mathrm{X}$ objective lens $(3.25 \mathrm{~m} /$ pixel). (b) Slice image with the $2 \mathrm{X}$ objective lens. (c) $3 \mathrm{D}$ reconstruction with the $10 \mathrm{X}$ objective lens $(0.65 \mathrm{~m} /$ pixel). (d) Slice image with the $10 \mathrm{X}$ objective lens.

particles with diameters ranging from several to several dozens of micrometers. In addition, water bridges with several dozens of micrometers in thickness are also observed between sand grains. As concerns the general structure of water (Figure $7(\mathrm{c})$ ), the radius of the water bridge is larger than that of the BioSpec glass beads because of the larger grain size for the Zhuhai sand. Water distribution is presented in Figure $7(\mathrm{~d})$, with gravimetric water contents varying from 6.6 to $13.9 \%$ and degrees of saturation from 10.0 to $19.9 \%$. The mean value of the water content, $9.3 \%$, is slightly smaller than the oven-drying value, i.e., 9.4\% (Table 3).

From the above, it can be concluded that the synchrotron-based $\mu$-CT is able to well characterize the $3 \mathrm{D}$ structure of granular materials such as glass beads and sand.
At the difference of the scanning electron microscope and Mercury intrusion porosimetry that require a delicate freeze drying step, moist samples can be directly scanned and water distribution can be determined both qualitatively and quantitatively. However, to ensure a satisfactory quality of the reconstructed image, any micromovement of soil grains and water phase should be avoided as much as possible during the rotation of the sample.

3.3. Water Distribution in the Compacted Clay. When preparing the Guangzhou clay sample, aggregates of several millimeters formed while water was added and mixed with the oven-dried clay particles (Figure 8). Water content of 
aggregates was determined, and its value (11.7\%) is $1.8 \%$ larger than the average value of the whole sample. $3 \mathrm{D}$ structure of the compacted sample, as presented in Figure 9(a), shows an aggregate-dominated skeleton structure. In the slice (Figure 9(b)), aggregates are clearly distinguishable due to the different greyscale values that result from the relatively larger water content. Under the effect of compaction effort, the size of aggregates decreases to several hundreds of micrometers in diameter. With a larger magnification, the micron-scale structure of the compacted sample is presented in Figures 9(c) and 9(d). The shape of a single aggregate is outlined by the dashed line in $\mathrm{YZ}$ and $\mathrm{XY}$ planes. It is found that the air-pores within aggregates are compressed to less than 10 micrometers. In these figures, however, it is still impossible to clearly observe the thin water films or water bridges within and outside aggregates.

A possible explanation of the above results is that the initial water content of $10 \%$ is too small for the clayey material to form water bridges that can be detected with a resolution of $0.65 \mu \mathrm{m}$. In fact, water absorption ability of the clays is much higher than that of granular material like glass or sand. The target water content of $10 \%$ during sample preparation should be mostly absorbed by voids between the platelets (i.e., within soil aggregates), and there should be very limited water remaining in the voids between the soil aggregates. To clearly detect the water phase within the soil aggregates, a higher resolution (e.g., in the scale of nanometer) is required.

\section{Conclusions}

Synchrotron-based $\mu$-CT tests were performed in order to determine the water distribution in different statically compacted materials. The results show the following:

(i) The addition of $20 \%$ in weight of iodine-based contrast medium (i.e., KI) can increase the greyscale value of the liquid from 110 to 122, enhance the air-water contrast and, and as a result, contribute to (semi)automatic segmentation of water phase.

(ii) In granular materials such as glass beads and sand, water distribution and water morphology are well determined, showing good capability of the $\mu$-CT to investigate the $3 \mathrm{D}$ structure of these materials.

(iii) In the case of the clayey soil, aggregates formed when water was mixed with the oven-dried clay particles and the water content within aggregates is larger than the average value of the whole sample; an aggregate-dominated 3D structure is observed for the compacted Guangzhou clay; in this study, it is impossible to clearly observe the thin water films within aggregates with the resolution of $0.65 \mu \mathrm{m} /$ pixel even though the micron-scale structure of soil grains and voids are distinguishable.

\section{Data Availability}

The micro-CT data used to support the findings of this study have been deposited in Professor Lian-Sheng Tang's repository.

\section{Conflicts of Interest}

The authors declare that they have no conflicts of interest.

\section{Acknowledgments}

The authors would like to acknowledge Dr. Ya-Nan FU at SSRF for her technical assistance and Zong Zhang and YanFang Zhang at Sanying Precision Instruments Co. Ltd. for their useful suggestions on graphic processing. This study was carried out at the beam-line BL13W1 of SSRF and financially supported by Natural Science Foundation of China (41572277 and 41877229).

\section{References}

[1] S. Ahmed, C. W. Lovell, and S. Diamond, "Pore sizes and strength of a compacted clay," ASCE Journal of Geotechnical Engineering, vol. 100, pp. 407-425, 1974.

[2] P. Delage and G. Lefebvre, "Study of the structure of a sensitive Champlain clay and of its evolution during consolidation," Canadian Geotechnical Journal, vol. 21, no. 1, pp. 21-35, 1984.

[3] R. Monroy, L. Zdravkovic, and A. Ridley, "Evolution of microstructure in compacted London clay during wetting and loading," Géotechnique, vol. 60, no. 2, pp. 105-119, 2010.

[4] R. Al-Raoush and A. Papadopoulos, "Representative elementary volume analysis of porous media using X-ray computed tomography," Powder Technology, vol. 200, no. 1-2, pp. 69-77, 2010.

[5] S. Y. Chung, T. S. Han, and Y. W. Kim, "Spatial distribution of voids in insulating concrete analyzed by micro-CT images and probability functions," Advances in Materials Science and Engineering, vol. 2015, Article ID 516169, 10 pages, 2015.

[6] M. A. Hashemi, T. J. Massart, S. Salager, G. Herrier, and B. François, "Pore scale characterization of lime-treated sandbentonite mixtures," Applied Clay Science, vol. 111, pp. 50-60, 2015.

[7] S. Katuwal, T. Norgaard, P. Moldrup, M. Lamandé, D. Wildenschild, and L. W. de Jonge, "Linking air and water transport in intact soils to macropore characteristics inferred from X-ray computed tomography," Geoderma, vol. 237-238, pp. 9-20, 2015.

[8] F. H. Kim, D. Penumadu, J. Gregor, N. Kardjilov, and I. Manke, "High-resolution neutron and X-ray imaging of granular materials," Journal of Geotechnical and Geoenvironmental Engineering, vol. 139, no. 5, pp. 715-723, 2013.

[9] F. H. Kim, D. Penumadu, J. Gregor, M. Marsh, N. Kardjilov, and I. Manke, "Characterizing partially saturated compactedsand specimen using 3D Image registration of high-resolution neutron and X-ray tomography," Journal of Computing in Civil Engineering, vol. 29, no. 6, article 04014096, 2015.

[10] L. Massat, O. Cuisinier, I. Bihannic et al., "Swelling pressure development and inter-aggregate porosity evolution upon hydration of a compacted swelling clay," Applied Clay Science, vol. 124-125, pp. 197-210, 2016.

[11] S. J. Mooney, “Three-dimensional visualization and quantification of soil macroporosity and water flow patterns using computed tomography," Soil Use and Management, vol. 18, no. 2, pp. 142-151, 2006.

[12] S. Saba, P. Delage, N. Lenoir, Y. J. Cui, A. M. Tang, and J.-D. Barnichon, "Further insight into the microstructure of 
compacted bentonite-sand mixture," Engineering Geology, vol. 168, pp. 141-148, 2014.

[13] J. P. Wang, P. Lambert, T. De Kock, V. Cnudde, and B. François, "Investigation of the effect of specific interfacial area on strength of unsaturated granular materials by X-ray tomography," Acta Geotechnica, pp. 1-15, 2019.

[14] C. S. Willson, N. Lu, and W. J. Likos, "Quantification of grain, pore, and fluid microstructure of unsaturated sand from X-ray computed tomography images," Geotechnical Testing Journal, vol. 35, no. 6, pp. 911-923, 2012.

[15] R. Alikarami, E. Andò, M. Gkiousas-Kapnisis, A. Torabi, and G. Viggiani, "Strain localisation and grain breakage in sand under shearing at high mean stress: insights from in situ X-ray tomography," Acta Geotechnica, vol. 10, no. 1, pp. 15-30, 2015.

[16] E. Andò, S. A. Hall, G. Viggiani, J. Desrues, and P. Bésuelle, "Grain-scale experimental investigation of localised deformation in sand: a discrete particle tracking approach," Acta Geotechnica, vol. 7, no. 1, pp. 1-13, 2012.

[17] S. A. Hall, M. Bornert, J. Desrues et al., "Discrete and continuum analysis of localised deformation in sand using X-ray $\mu \mathrm{CT}$ and volumetric digital image correlation," Géotechnique, vol. 60 , no. 5, pp. 315-322, 2010.

[18] Y. Higo, F. Oka, S. Kimoto, T. Sanagawa, and Y. Matsushima, "Study of strain localization and microstructural changes in partially saturated sand during triaxial tests using microfocus X-ray CT," Soils and Foundations, vol. 51, no. 1, pp. 95-111, 2011.

[19] Y. Higo, F. Oka, T. Sato, Y. Matsushima, and S. Kimoto, "Investigation of localized deformation in partially saturated sand under triaxial compression using microfocus X-ray CT with digital image correlation," Soils and Foundations, vol. 53, no. 2, pp. 181-198, 2013.

[20] M. Oda, T. Takemura, and M. Takahashi, "Microstructure in shear band observed by microfocus X-ray computed tomography," Géotechnique, vol. 54, no. 8, pp. 539-542, 2004.

[21] D. Takano, N. Lenoir, J. Otani, and S. A. Hall, "Localised deformation in a wide-grained sand under triaxial compression revealed by X-ray tomography and digital image correlation," Soils and Foundations, vol. 55, no. 4, pp. 906915, 2015.

[22] G. Viggiani, N. Lenoir, P. Besuelle et al., "X-ray microtomography for studying localized deformation in finegrained geomaterials under triaxial compression," Comptes Rendus Mécanique, vol. 332, no. 10, pp. 819-826, 2004.

[23] F. N. Altuhafi and M. R. Coop, "Changes to particle characteristics associated with the compression of sands," Géotechnique, vol. 61, no. 6, pp. 459-471, 2011.

[24] M. B. Cil and K. A. Alshibli, "3D evolution of sand fracture under 1D compression,” Géotechnique, vol. 64, no. 5, pp. 351-364, 2014.

[25] Z. Karatza, E. Andò, S. A. Papanicolopulos, J. Y. Ooi, and G. Viggiani, "Evolution of deformation and breakage in sand studied using X-ray tomography," Géotechnique, vol. 68, no. 2, pp. 107-117, 2018.

[26] H.-Y. Zhang, W.-J. Xu, and Y.-Z. Yu, "Triaxial tests of soilrock mixtures with different rock block distributions," Soils and Foundations, vol. 56, no. 1, pp. 44-56, 2016.

[27] B. Zhao, J. Wang, M. R. Coop, G. Viggiani, and M. Jiang, “An investigation of single sand particle fracture using X-ray micro-tomography," Géotechnique, vol. 65, no. 8, pp. 625-641, 2015.

[28] J. Fonseca, C. O’Sullivan, M. R. Coop, and P. D. Lee, "Noninvasive characterization of particle morphology of natural sands," Soils and Foundations, vol. 52, no. 4, pp. 712-722, 2012.

[29] B. Zhao and J. Wang, "3D quantitative shape analysis on form, roundness, and compactness with $\mu \mathrm{CT}$," Powder Technology, vol. 291, pp. 262-275, 2016.

[30] B. Zhou, J. Wang, and B. Zhao, "Micromorphology characterization and reconstruction of sand particles using micro X-ray tomography and spherical harmonics," Engineering Geology, vol. 184, pp. 126-137, 2015.

[31] B. Zhou, J. Wang, and H. Wang, "Three-dimensional sphericity, roundness and fractal dimension of sand particles," Géotechnique, vol. 68, no. 1, pp. 18-30, 2018.

[32] E. Andò, S. A. Hall, G. Viggiani, J. Desrues, and P. Bésuelle, "Experimental micromechanics: grain-scale observation of sand deformation," Géotechnique Letters, vol. 2, no. 3, pp. 107-112, 2012.

[33] J. E. Andrade and C. F. Avila, "Granular element method (GEM): linking inter-particle forces with macroscopic loading," Granular Matter, vol. 14, no. 1, pp. 51-61, 2012.

[34] J.-F. Bruchon, J.-M. Pereira, M. Vandamme, N. Lenoir, P. Delage, and M. Bornert, "Full 3D investigation and characterisation of capillary collapse of a loose unsaturated sand using X-ray CT," Granular Matter, vol. 15, no. 6, pp. 783-800, 2013.

[35] Z. Cheng and J. Wang, "Experimental investigation of interparticle contact evolution of sheared granular materials using X-ray micro-tomography," Soils and Foundations, vol. 58, no. 6, pp. 1492-1510, 2018.

[36] A. Hasan and K. A. Alshibli, "Experimental assessment of 3D particle-to-particle interaction within sheared sand using synchrotron microtomography," Géotechnique, vol. 60, no. 5, pp. 369-379, 2010.

[37] Y. Watanabe, N. Lenoir, J. Otani, and T. Nakai, "Displacement in sand under triaxial compression by tracking soil particles on X-ray CT data," Soils and Foundations, vol. 52, no. 2, pp. 312-320, 2012.

[38] N. Lenoir, "Comportement mécanique et rupture dans les roches argileuses étudiés par micro tomographie a rayons $\mathrm{X}$," Doctoral dissertation, Université Joseph-Fourier-Grenoble I, Saint-Martin-d'Hères, France, 2006, in French.

[39] S. S. Alrwashdeh, H. Markötter, J. Haußmann et al., "Investigation of water transport dynamics in polymer electrolyte membrane fuel cells based on high porous micro porous layers," Energy, vol. 102, pp. 161-165, 2016.

[40] G. J. Kazakia, A. J. Burghardt, S. Cheung, and S. Majumdar, "Assessment of bone tissue mineralization by conventional $\mathrm{x}$-ray microcomputed tomography: comparison with synchrotron radiation microcomputed tomography and ash measurements," Medical Physics, vol. 35, no. 7Part1, pp. 3170-3179, 2008.

[41] H. Bale, M. Blacklock, M. R. Begley, D. B. Marshall, B. N. Cox, and R. O. Ritchie, "Characterizing three-dimensional textile ceramic composites using synchrotron X-ray micro-computed-tomography," Journal of the American Ceramic Society, vol. 95, no. 1, pp. 392-402, 2012.

[42] A. Lavrov, E. A. C. Panduro, and M. Torsæter, "Synchrotron study of cement hydration: towards computed tomography analysis of interfacial transition zone," Energy Procedia, vol. 114, pp. 5109-5117, 2017.

[43] M. A. B. Promentilla, T. Sugiyama, T. Hitomi, and N. Takeda, "Quantification of tortuosity in hardened cement pastes using synchrotron-based X-ray computed microtomography," Cement and Concrete Research, vol. 39, no. 6, pp. 548-557, 2009. 
[44] Y. Higo, R. Morishita, R. Kido, G. Khaddour, and S. Salager, "Local water-retention behaviour of sand during drying and wetting process observed by micro x-ray tomography with trinarisation," Japanese Geotechnical Society Special Publication, vol. 2, no. 16, pp. 635-638, 2016.

[45] C. T. Chantler, K. Olsen, R. A. Dragoset et al., X-Ray Form Factor, Attenuation and Scattering Tables, National Institute of Standards and Technology, Gaithersburg, MD, USA, 2017, http://physics.nist.gov/ffast.

[46] R. Tippkötter, T. Eickhorst, H. Taubner, B. Gredner, and G. Rademaker, "Detection of soil water in macropores of undisturbed soil using microfocus X-ray tube computerized tomography $(\mu \mathrm{CT})$," Soil and Tillage Research, vol. 105, no. 1, pp. 12-20, 2009.

[47] M. Scheel, R. Seemann, M. Brinkmann et al., "Morphological clues to wet granular pile stability," Nature Materials, vol. 7, no. 3, pp. 189-193, 2008.

[48] L. Yang, Y. Zhang, Z. Liu, P. Zhao, and C. Liu, "In-situ tracking of water transport in cement paste using X-ray computed tomography combined with $\mathrm{CsCl}$ enhancing," Materials Letters, vol. 160, pp. 381-383, 2015.

[49] F. H. Kim, D. Penumadu, and D. S. Hussey, "Water distribution variation in partially saturated granular materials using neutron imaging," Journal of Geotechnical and Geoenvironmental Engineering, vol. 138, no. 2, pp. 147-154, 2012.

[50] D. Snoeck, S. Steuperaert, K. Van Tittelboom, P. Dubruel, and N. De Belie, "Visualization of water penetration in cementitious materials with superabsorbent polymers by means of neutron radiography," Cement and Concrete Research, vol. 42, no. 8, pp. 1113-1121, 2012.

[51] D. Van Loo, L. Bouckaert, O. Leroux et al., "Contrast agents for soil investigation with X-ray computed tomography," Geoderma, vol. 213, no. 1, pp. 485-491, 2014.

[52] R.-C. Chen, D. Dreossi, L. Mancini et al., "PITRE: software for phase-sensitive X-ray image processing and tomography reconstruction," Journal of Synchrotron Radiation, vol. 19, no. 5, pp. 836-845, 2012. 


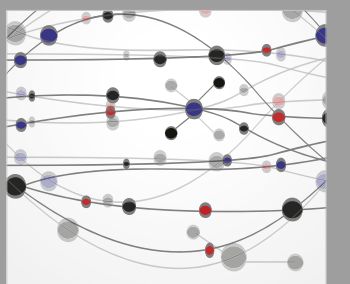

The Scientific World Journal
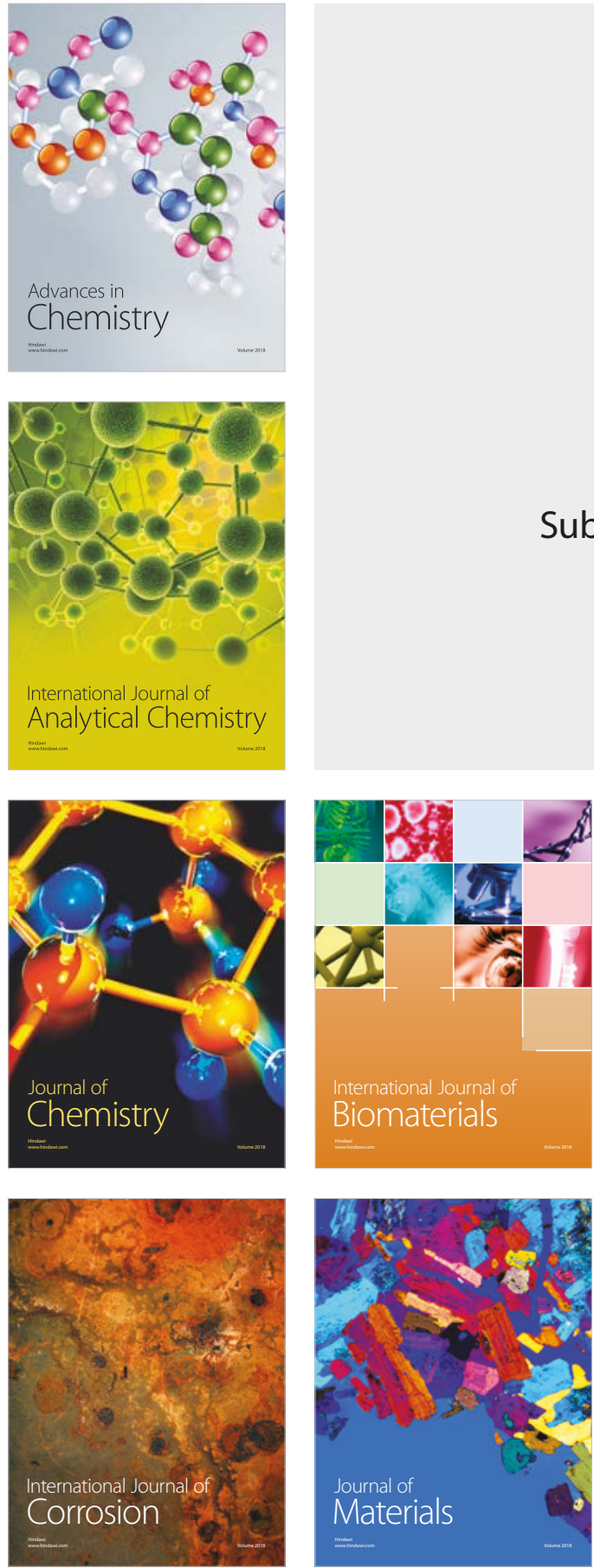

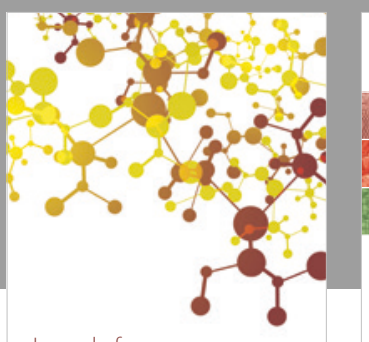

Journal of

Applied Chemistry
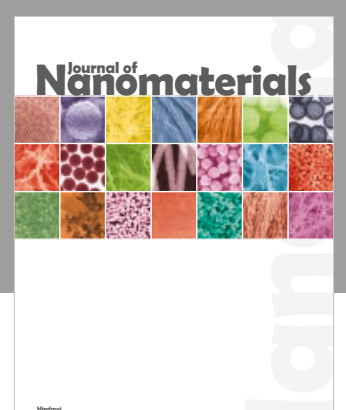

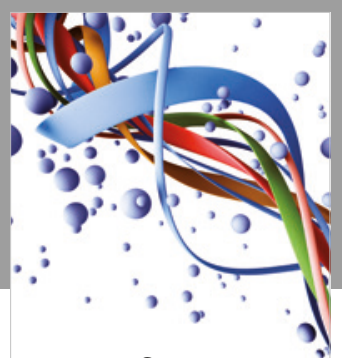

Scientifica

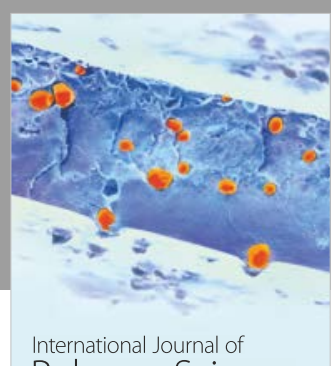

Polymer Science

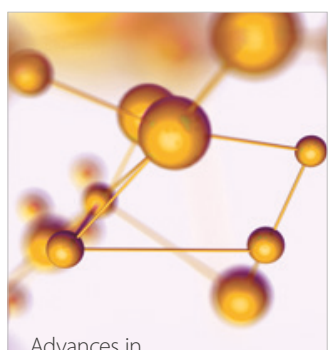

Physical Chemistry
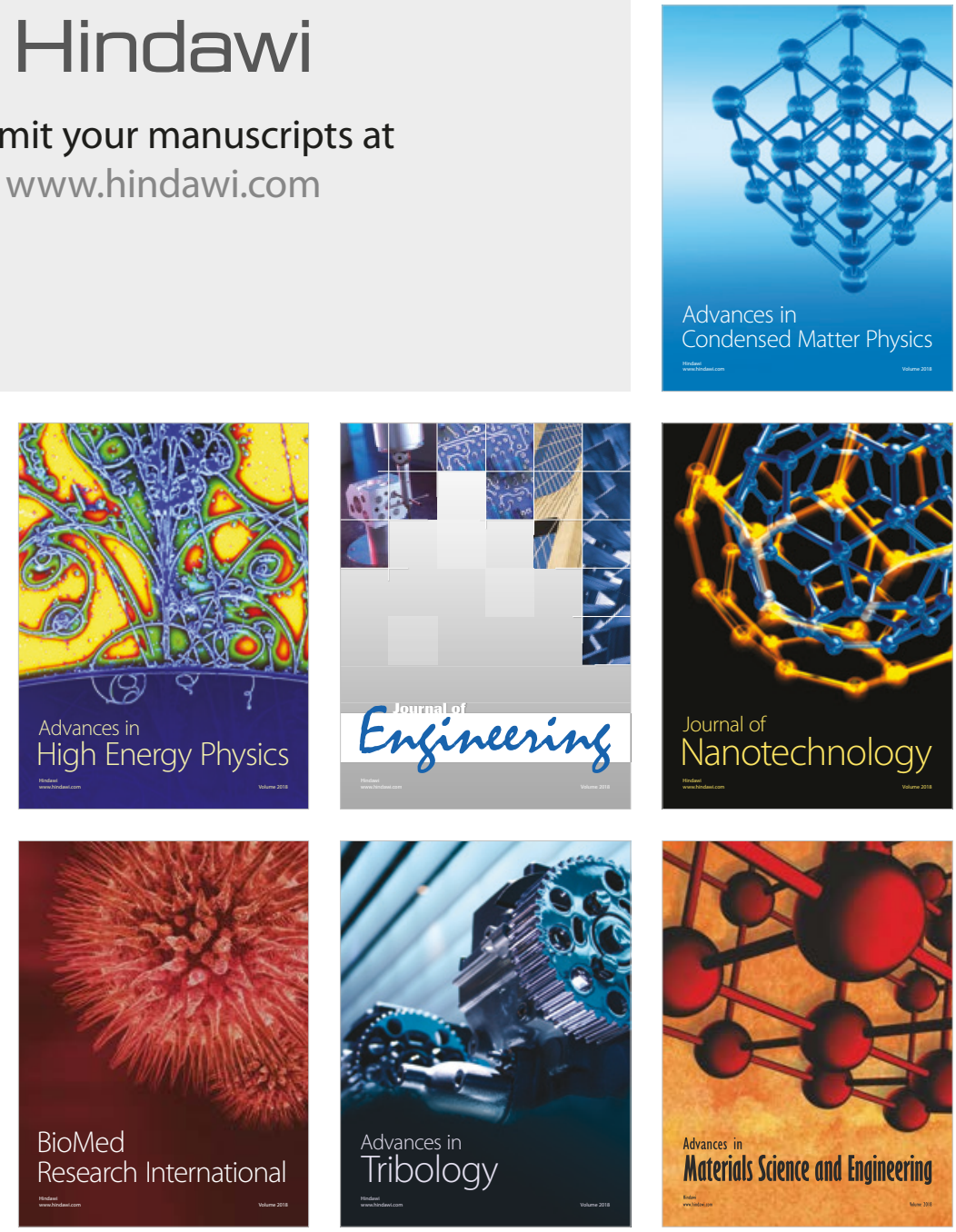